\title{
Problem Identification and Task Engagement Using the LIBRE Problem Solving Tool: A Case Study of Three Bilingual Teacher Candidates
}

\author{
Norma Guerra ${ }^{1}$, Felicia Castro-Villarreal ${ }^{1}$, Nicholas Cheatham ${ }^{1}$, Lorena Claeys ${ }^{2}$ \\ ${ }^{1}$ College of Education and Human Development, University of Texas, San Antonio, Texas, USA \\ ${ }^{2}$ Academy of Teacher Excellence, University of Texas, San Antonio, Texas, USA \\ Correspondence: Norma Guerra, PhD., College of Education and Human Development, Department of Educational \\ Psychology, 501 West César E. Chàvez Blvd, San Antonio, Texas 78207, USA
}

Received: April 23, 2014

doi:10.11114/jets.v2i3.396

Online Published: May 26, 2014

URL: http://dx.doi.org/10.11114/jets.v2i3.396

\begin{abstract}
Bilingual Latino students engage multiple languages, cultures and environments as they pursue educational and professional goals. For this underrepresented group, pursuing a post-secondary degree is a "lucha" (fight) to negotiate the complex interplay of historical, educational, and cultural variables and achieve academic success. Because Bilingual Latino teacher success is incumbent upon successfully negotiating and overcoming linguistic, cultural and educational challenges, examination of problem solving and goal setting is necessary to provide insight into the types of barriers and facilitators that this group experiences and the ways in which they overcome obstacles. An in-depth case study of three bilingual teacher candidates illustrates the use of the LIBRE problem-solving tool as a culturally responsive activity involving a sequence of problem identification, analysis, solution generation, and evaluation to facilitate problem resolution. The case studies examined herein illuminate self-reported social-cultural contextual challenges, solutions, goals, and engagement through explicit problem solving and shows the primacy of familia and cultura in these women's lives, problem-solving, and decision making. Implications for teacher educators and bilingual Latino teacher candidates are discussed.
\end{abstract}

Keywords: problem solving, bilingual teachers, teacher education, consultation, bilingual education

\section{Introduction}

When Alicia, a first-generation college student decided to return to school full-time for a bachelor's degree in bilingual education, she expected it to be a challenge. She felt confident in her current food service position; she was well versed in English and Spanish, yet when considering college life, she was uncertain where she would fit in as a non-traditional and Latina student. Most of her peers knew someone who went to college, had English as their first language, and many knew someone who had become a teacher. As a first-generation college student, Alicia had no educational role models. Nonetheless, she was determined to be successful and she was prepared to invest her all. As many Latino college students share (Clark, \& Flores, 2005; Castro-Villarreal \& Guerra, 2012), she had sacrificed quite a bit for this endeavor and soon found herself running between work, school, and family. Alicia reported having little time for family and friends and no time for self. Despite these challenges, Alicia anticipates graduating at the end of the summer and is confident that she will be a great bilingual education teacher and role model.

Just like Alicia, Katia shares the same ambition to teach. She aspires to become a bilingual education teacher however her path is somewhat different. She is a non-traditional student who attends school part-time while working full-time as an arcade attendant and she has always been able to find a job in large part because she is bilingual. Katia supports herself financially and as a result is moving slowing through her undergraduate studies (6+years). Her mother reportedly suffers from a chronic illness and she is in conflict with her brother concerning the family business that their deceased father left the family. Similar to Alicia, Katia also reports having no free time and few friends. Still, Katia describes herself as dedicated and determined to make a difference in the lives of her future students.

Maggie is also a first generation bilingual student aspiring to be the best bilingual education teacher possible, but she lacks family support. She attends school full-time while working as a supervisor at a pretzel shop in the mall and is certain that she was hired because she speaks two languages and is not afraid to be a leader. She feels fortunate that although her immediate family members do not understand her desire to pursue postsecondary education to become a 
bilingual education teacher, that her friends are very supportive. She believes in herself and is looking forward to educating bilingual students but her current situation involves an intense struggle to balance work, school, and family.

The present case studies feature three bilingual teacher candidates who are equally committed to pursuing a postsecondary degree toward becoming bilingual education teachers. They each express a strong desire to help students learn. While their motivation and sacrifices are evident in their stories, Latino students experience a myriad of challenges associated with educational, familial, and cultural norms and expectations that often conflict with the pursuit of a postsecondary degree. In addition to personal and cultural challenges, the classroom is a complex environment that is but one aspect of a student's ecology where good problem solving skills are critical to survival (Castro-Villarreal \& Guerra, 2012). What we see in these cases are significant personal challenges and what we know is that there are educational, societal and cultural challenges that serve to compound the need for expert problem solving (Castro-Villarreal \& Guerra, 2012). Framed within the context of Latino cultural values and Social Cognitive theory (Bandura, 2001), three cases are presented to illuminate the complexities and difficulties that Latina bilingual teacher candidates face when pursuing a postsecondary degree. These cases also demonstrate the utility of the LIBRE problem solving tool as a way to facilitate task engagement and goal setting to aid in effective problem solving. Through the espoused narratives and completed problem solving tools, barriers and facilitators to pursuing a postsecondary degree are highlighted to shed light on some of the characteristics that contribute to the achievement of educational and professional success for Latina bilingual teacher candidates.

\section{The State of Public Education}

The ethnic and cultural composition of the U.S. student body is changing as ethnic minority student enrollment in public elementary and secondary school is projected to increase by 33\% before the year 2022 (U.S. Department of Education, 2013). Latino children represent one of the fastest growing subgroups, second only to biracial or mixed ethnicity students who are projected to increase by $44 \%$ by the year 2022 (U.S. Department of Education, 2013). To add yet another layer of complexity, $11 \%$ of Latino students are also bilingual and categorized as English Language Learners (ELLs) (U.S. Department of Education, 2013). Unfortunately, Latino and biracial students are more likely to attend public schools that are underfunded, in lower socio-economic communities, and staffed by uncertified teachers (Darling-Hammond, 2004). When compared to their Caucasian counterparts, Latino students show lower academic achievement and consistently record some of the highest dropout rates (Llagas \& Snyder, 2003; U.S. Department of Education, 2013). Approximately one out of three Latino students will drop out of school (Lopez \& Fry, 2013). The changing face of the U.S. student body suggests that teachers face complex challenges that require complex problem solving. However, at the same time our teacher pool is becoming less diverse as a bilingual teacher shortage has long been noted (Hollins\& Guzman, 2005). Almost $76 \%$ of public school teachers are female and $83 \%$ are Caucasian, only $7 \%$ are Black or Hispanic, and less than $1 \%$ report being biracial (U.S. Department of Education, 2012). These numbers underscore the mismatch between the U.S. student body and teachers. The complexities of the changing U.S. student demographic combined with a shortage of ethnic minority teachers, suggests the need for in depth and qualitative analysis of successful Latina bilingual teacher candidates in order to elucidate some of the factors that foster successful problem solving.

\subsection{Latina Bilingual Teacher Candidate Training Need}

Considering that in less than three decades the majority of students will likely be ethnically diverse, attention to the lived experiences of Latina bilingual teacher candidates is necessary if we are to prepare teachers to respond to this changing demographic. A recent report suggests that students learn better if taught by teachers of similar ethnic backgrounds (Schmitz, Nourse, \& Ross, 2013). Moreover, research has shown that teacher quality is central to student success, particularly for low income and culturally and linguistically diverse students (Haycock, 2002). Therefore, researchers have called for a unique and individually tailored training model for bilingual teacher preparation (Clark \& Flores, 2005). Transformacion (Transformation) (Flores, Clark, Claeys, \& Villarreal, 2007) is one such teacher preparation model that focuses on self-reflection, goal setting, and identity development. The tenets of this model suggest that teacher quality extends beyond content knowledge to include teachers' ability to engage in critical self-reflection, planning, and problem solving (Haycock, 2002). These central constructs combine to contribute to the development of teaching efficacy, another central component of the model based on previous research that has shown a relation between efficacy and effective problem solving (Castro-Villarreal \& Guerra, 2012; Hsieh, Sullivan, \& Guerra, 2007).Considering the emphasis on self-reflection and goal setting in bilingual teacher preparation, it appears important to examine these characteristics in bilingual teacher candidates.

\section{Conceptual and Theoretical Framework}

\subsection{Culture and Family}

While Latinos represent a diverse and heterogeneous group, they share common core values and are characterized as a collectivist culture that values warm, emotionally positive social interaction and places particular importance on familia 
(Sanchez-Burks, Nisbett, \& Ybarra, 2000). For example, a strong sense of togetherness, belonging, and interdependency in shared support, is found within the Latino culture but primarily seen and studied in Mexican Americans (Briones, Heller, Chalfant, Roberts, Aguirre-Hauchbaum, \& Farr, 1990). The idea of Familismo, which means loyalty, solidarity, cooperation, and interdependence is said to be cornerstone to identity and educational and professional development (Falicov, 1996). Thus for a Latina, these cultural values frame identity and professional development and play central roles in goal setting and decision making. Due to the emphasis on family relationships, these relationships and/or lack thereof are particularly salient in the lives of Latinas and often have significant influence on decision making (Saldana, Castro-Villarreal, \& Sosa, 2013).

\subsection{Social Cognitive Theory and Problem Solving}

Social cognitive theory recognizes the role of culture in behavior and explains behavior as an interaction between person, environment, and social and cultural experiences (Bandura, 1986; Connell \& Wellborn, 1991). Conceptualized in this way, behavior, problem-solving, and decision making are believed to be strongly influenced by a person's worldview, cultural values, and belief system. Self-regulation is a construct important to behavior and problem solving and is conceptualized as self-generated thoughts, feelings, and actions adopted in the pursuit of personal goals (Zimmerman, 2000). As an individual moves from one language and environmental context to another, self-regulation becomes essential in balancing and managing multiple goals and therefore should be monitored within the problem solving process. Researchers would do well to examine person's decision making processes to begin to understand the types of values and beliefs that comprise problem-solving. Utilizing social cognitive theory as a theoretical framework, researchers would do well to examine person's decision making processes to begin to understand the types of values and beliefs that comprise problem-solving.

\subsection{Teachers as Problem Solvers}

Problem solving is one of the most important cognitive processes in everyday life and as such should be given greater attention in teacher education (Castro-Villarreal, \& Guerra, 2012; Mayer \& Wittrock, 2006). Teachers are confronted with a myriad of problems in the classroom and if they lack the capacity to solve problems, how can they teach students to problem solve? Research has shown notable differences in problem solving approaches between novice and experienced teachers. Experienced teachers are better able to immediately hone in on essential problem features while the novice teacher is more likely to feel overwhelmed and to attend to irrelevant and extraneous features (Anderson, 1993; Basile, Olson, \& Nathenson-Mejia, 2003; Castro-Villarreal \& Guerra, 2012; Evans, \& Tribble, 1986; Hogan, \& Rabinowitz, 2009; Kilbane, 2008; Mayer \& Wittrock, 2006; Swanson, O'Connor \& Cooney, 1990). Experienced teachers showed more elaborate strategy statements and spent more time defining and operationalizing the problem (Castro-Villarreal \& Guerra, 2012; Jolly \& Jacob, 2012). Other research found efficient problem solvers showed flexible and organized knowledge in order to manage and apply skills for effective problem solving (Castro-Villarreal \& Guerra, 2012; Jolly \& Jacob. 2012). Findings suggest that effective problem solvers spend considerably more time identifying problems and relevant problem features and also exhibit goal-oriented planning and problem resolution (Castro-Villarreal \& Guerra, 2012).

\subsection{Problem Solving and Engagement}

Task engagement is critical to identifying essential problem features for effective problem solving. Research on engagement and self-regulation monitors these cognitive processes through problem-solving in the quantity and quality of identified problems, plans, and problem solutions (Castro-Villarreal \& Guerra, 2012; Guerra, 2006; Guerra, \& Bollinger, 2011). As a means to monitor task engagement, four distinct engagement styles have been identified through research: (a) Actual Engagement-a total initial and sustained attentive investment, (b) Goal focused engagement-limited initial attention with a pronounced sustained attentive investment, (c) Venting engagement- a strong initial attentiveness with no sustained interest or desire to address change, and (d) Potential engagement- exhibits no initial or sustained attention (Guerra, 2009).

\section{Purpose of the Research}

To address the shortages of Latinos in teaching, we must learn from challenges and successes at the individual level (Flores et al., 2007; Irizarry, 2011). Moreover, to begin to prepare teachers for the myriad of problems they will face in the classroom, it is necessary to first identify and categorize the types of problems teachers face and determine the cognitive skills needed for effective problem solving. Framed within social cognitive theory and a sociocultural problem-solving paradigm, this study provides a snapshot of three Latina bilingual teacher candidates as they pursue personal and professional goals described in terms of their challenges and plans to illustrate how effective problem solving can aid in the development of teaching efficacy and professional and identity development. 


\section{Research Questions}

The questions examined within this case study are: (1) Identified social cognitive challenges: What do bilingual teacher candidates identify as social cognitive concerns? (2) Identified goals - what are their goals? (3) Engagement- what is the initial and sustained attention to challenges for each bilingual teacher candidate as expressed in their problem identification and resolution? (4) What can be learned from these case studies about the role of family, culture, and cognition in the decision to pursue teaching? and (5) What can be learned from their problem solving approaches as a means to foster effective practices in other teacher candidates?

\section{Method}

\subsection{Research Participants and Design}

The three Latina Bilingual teacher candidates under examination were drawn from a larger longitudinal project that examined 23 bilingual teacher candidates' problem solving, engagement, and goal setting. Purposeful sampling was employed where three cases determined to represent "actual engaged" problem solving styles of Latina Bilingual teacher candidates' challenges and problem solving skills were selected. See Table 1 for demographic information. A qualitative case study approach involving cross-case analysis was utilized to enable in depth and contextual study of three bilingual teacher candidates (Merriam, 2009). This methodology was selected in order to explore multiple bounded systems over time involving multiple sources of information that also served to increase internal validity and generalizability. Selected themes were explored in response to the research questions and patterns were examined with data triangulation completed through observations and interviews (Merriam, 2009). See Table 1 for demographic information. Participants completed the LIBRE problem-solving tool individually and a follow up semi-structured interview that accompanies administration of the LIBRE problem solving tool was conducted on the same date.

Table 1. Demographic Information

\begin{tabular}{lccc}
\hline & Alicia & Katia & Maggie \\
\hline First Generation & $\checkmark$ & $\checkmark$ & $\checkmark$ \\
Gender/Female & $\checkmark$ & $\checkmark$ & $\checkmark$ \\
Full-Time Student & $\checkmark$ & & $\checkmark$ \\
Language Spoken in the & Spanish & Spanish & $\checkmark$ \\
Home & & & $\checkmark$ \\
Working Full Time & $\checkmark$ & & $\checkmark$ \\
Traditional Age & $\checkmark$ & & \\
Friend Support & & $\checkmark$ & \\
Family Support & $\checkmark$ & & \\
\hline
\end{tabular}

\subsection{LIBRE Problem Solving Tool}

Data were collected using the LIBRE problem solving tool (See Figure 1). Similar to other problem solving instruments, this tool is designed to guide the problem solving process (Guerra, 2006, 2009). The model consists of the following five steps: L-listening: teacher candidates listening to themselves and listing the problems they are currently experiencing; I-identify: teacher candidates choose one of their listed problems from the $\mathrm{L}$ section to focus on; $B$-brainstorming: involves producing ideas that will directly or indirectly help teacher candidates explore their willingness to work through their identified problem; $R$-reality testing: exploration of realistic plans of action based on the options listed above in the B section; E-encourage: when teacher candidates are encouraged to create a course of action towards resolving their problem. This includes measureable outcomes and timelines. The prompts for these five steps are all found on a stick figure graphic organizer that is used to assist in the LIBRE problem solving model activity (Guerra, 2009).

Administration of the LIBRE problem solving tool involved trained facilitators who used open-ended questions to guide teacher candidates with problem identification. The open-ended problem solving approach was selected to allow each teacher candidate to address any type of selected challenge (school, work or personal). The structured prompts function as a skeletal outline but allow participants maximum freedom to express unique social contextual challenges. This approach is based on literature that suggests that more information is gathered if an open-ended approach is assumed (Au \& Blake, 2003; Day \& Leitch, 2001) and the problem-solving tool is supported by literature that suggests a visual problem-solving tool can be useful in self-regulating and self-monitoring (Castro-Villarreal \& Guerra, 2012; 
Zimmerman \& Schunk, 2004).

The three teacher candidates' problem solving narratives composed the cross-case analysis (Glaser \& Strauss, 1967, 1970). Associated LIBRE model interviews were conducted to allow for queries and explanation of responses provided on the LIBRE problem solving tool. The interviews lasted approximately one hour and were structured by the LIBRE model prompts (See Figure 1).

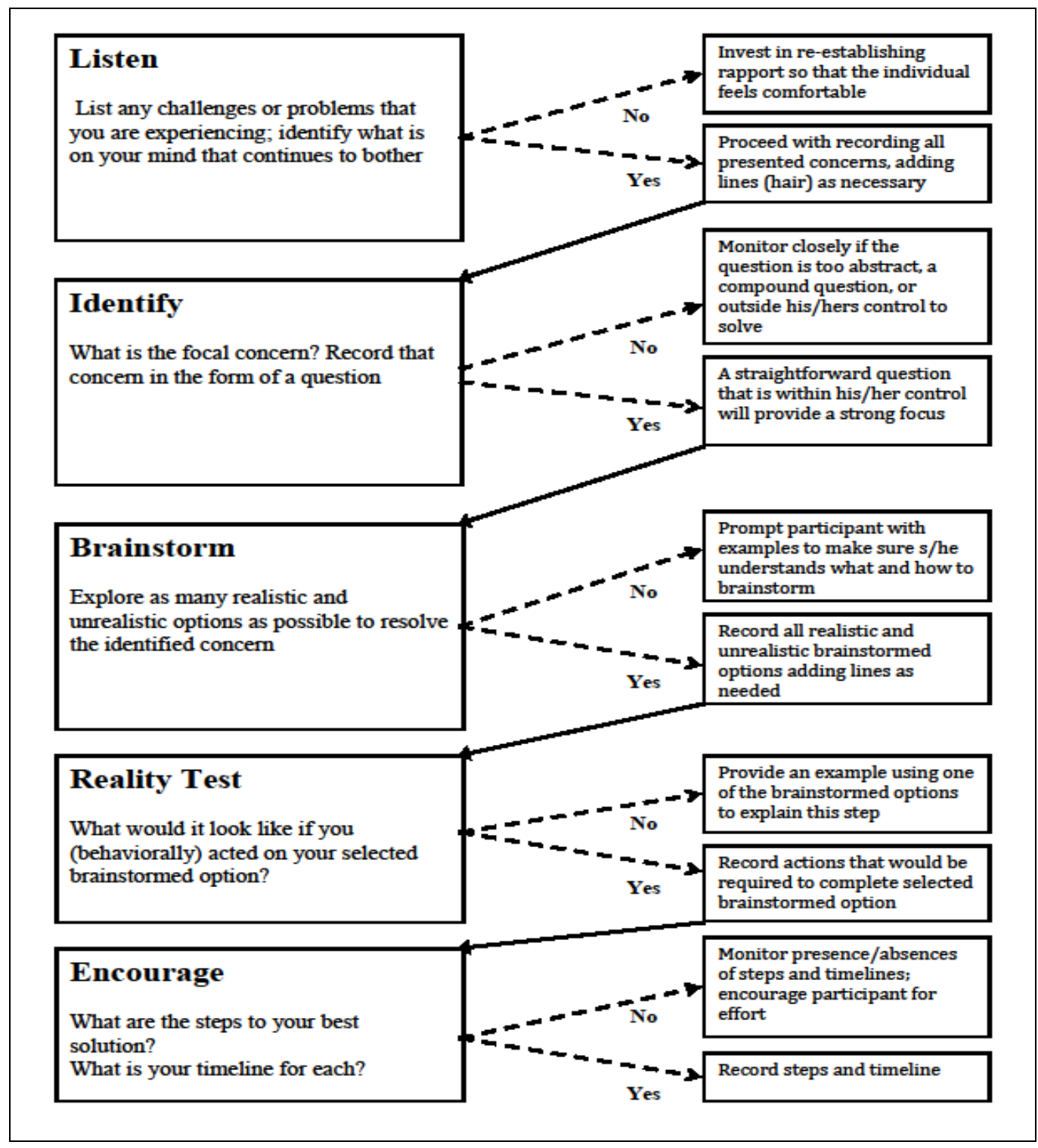

Figure 1. LIBRE Model Administration Process (Guerra, 2009)

\section{Results}

\subsection{Case Descriptions and Case Based Themes}

Table 2 presents the individual responses to the problem solving prompts provided. Each bilingual teacher candidate was administered the LIBRE problem solving tool and asked to provide as much or as little detail as desired. Two independent researchers analyzed LIBRE Model responses and a grounded theory constant comparison approach was utilized (Glaser \& Strauss, 1970). Themes were examined based on the LIBRE Model prompts. For example, a "types of challenges" theme was extracted based on the "listen and list challenges" prompt of the LIBRE Model. Decision-making and solution generation themes were based on the "encourage" prompt of the model. Each LIBRE Model prompt served as a category to explore for patterns and cross-case analysis. 
Table 2. LIBRE Responses for Latina Bilingual Teacher Candidates

\begin{tabular}{|c|c|c|c|}
\hline $\begin{array}{l}\text { LIBRE } \\
\text { Steps } \\
\end{array}$ & Alicia & Katia & Maggie \\
\hline Listen & $\begin{array}{l}\text { - } \text { Getting work done. } \\
\text { - } \text { Time management. } \\
\text { - } \text { Managing my finances. } \\
\text { - } \quad \text { Family troubles. } \\
\text { pinishing school \& able to } \\
\text { pay. }\end{array}$ & $\begin{array}{l}\text { Dealing with my mom's "recovering } \\
\text { stage." } \\
\text { - My brother's struggle to take over } \\
\text { dad's company. } \\
\text { - Ending of the semester. } \\
\text { Dealing with work. }\end{array}$ & $\begin{array}{ll}\text { - } & \text { Assignments. } \\
\text { - } & \text { Responsibilities. } \\
\text { - } & \text { Fundraising events. } \\
\text { - } & \text { Finals. } \\
\text { - } & \text { Meetings. } \\
\text { - } & \text { Family. } \\
\text { - } & \text { Home. } \\
\end{array}$ \\
\hline Identify & $\begin{array}{l}\text { What can I do to help me manage } \\
\text { my time better? }\end{array}$ & How can I deal with the stress of my job? & How do I begin to prioritize? \\
\hline Brainstorm & $\begin{array}{ll}\text { - } & \text { Buy a planner. } \\
\text { - } & \text { Make lists. } \\
\text { - } & \text { Set reminders for work/chores. }\end{array}$ & $\begin{array}{ll}\text { - } & \text { Maybe let them know that I need } \\
\text { some time off. } \\
\text { - } \\
\text { - } \quad \text { Mayk out a new schedule. } \\
\text { whole day. }\end{array}$ & $\begin{array}{l}\text { - } \quad \text { Turn things in late. } \\
\text { - } \quad \text { Give up. } \\
\text { - } \quad \text { Do one assignment at a time. } \\
\text { - }\end{array}$ \\
\hline $\begin{array}{l}\text { Reality } \\
\text { Test }\end{array}$ & $\begin{array}{l}\text { Buy a planner/calendar to be } \\
\text { able to jot down any important } \\
\text { due dates. }\end{array}$ & $\begin{array}{l}\text { Talk to my boss and figure out a } \\
\text { way to get some time off. } \\
\text { A new schedule may result in less } \\
\text { money. } \\
\text { - Going to work half-days would give } \\
\text { me more time to myself. }\end{array}$ & $\begin{array}{l}\text { - } \quad \text { Low grades. } \\
\text { - } \quad \text { Will not be able to succeed. } \\
\text { - } \quad \text { Uet further behind. } \\
\text { Use a calendar to do } 2-3 \\
\text { assignments a day. }\end{array}$ \\
\hline \multirow[t]{4}{*}{ Encourage } & Steps to best Solution & Steps to best Solution & Steps to best Solution \\
\hline & $\begin{array}{l}\text { - I can buy a planner \& post-it } \\
\text { notes. } \\
\text { I can carry the planner with me } \\
\text { to make notes on important } \\
\text { dates. } \\
\text { With post-it notes, I can } \\
\text { re-write the dates and post } \\
\text { them around the house as } \\
\text { reminders. }\end{array}$ & $\begin{array}{l}\text { - Have a meeting with my boss and } \\
\text { coworkers. } \\
\text { Explain that I feel too stressed and } \\
\text { that everything falls on my } \\
\text { shoulders at work. } \\
\text { I would ask for some days off and } \\
\text { see about reducing my weekly work } \\
\text { schedule. }\end{array}$ & $\begin{array}{l}\text { Use calendar to do } 3 \\
\text { assignments per day. } \\
\text { - Call a classmate. } \\
\text { Communicate with my } \\
\text { family and let them know my } \\
\text { limitations. }\end{array}$ \\
\hline & Written Action Plan & Written Action Plan & Written Action Plan \\
\hline & $\begin{array}{l}\text { Friday before work, go to the } \\
\text { store to buy a planner and } \\
\text { post-it notes. }\end{array}$ & $\begin{array}{l}\text { By the end of the week, I will set a } \\
\text { meeting with my boss and explain } \\
\text { everything to let them know what I } \\
\text { need as of now. }\end{array}$ & $\begin{array}{l}\text { - } \\
\text { met timeframe and put it in } \\
\text { bathroom mirror. } \\
\text { - } \quad \text { Call a friend on to get update. } \\
\text { - } \quad \text { Talk to family on the } \\
\text { weekend about your plan. }\end{array}$ \\
\hline
\end{tabular}

For Alicia, keeping up with work completion, time management, financial responsibilities, finishing school and family troubles were identified as challenges at the surface level. Such responsibilities (financial, time management and school completion) may be stressful for those, such as Alicia, who are first within their families to attend and aim to complete college (Cushman, 2006). At the deeper structure were the associated relationships that lead her to explore how to better manage time with responses that led to a solution of investing in a planner and setting up a reminder system using post-it notes. In contrast, Katia who as a non-traditional student (attending school part-time), reports her surface concerns not only with herself but also with her mother's health, her brother's struggle, finishing school and stress caused by work. At a deeper level is the associated stress that she selected to contextualize in relationship to her full-time job. She generated a plan that involved her negotiating days off from work with her boss and co-workers. Maggie presents a surface level of social context filled with schoolwork (assignments and finals), school activity (fundraiser \& event), and family (home). At a deeper level is her need to self-regulate as she presses forward to problem solve, "How do I begin to prioritize?" Maggie's plan to prioritize also involves investment in a calendar as well as using a note system to remind her of what assignments she needs to complete. It is the self-awareness and recognition however that is critical. Bandura (1982) and Meichenbaum (1977) provide identifiable differences between effective problem solvers and non-effective problem solvers. Individuals who are self-aware, insightful, hold a strong self-concept and self-efficacy extend in investment, while ineffective problem solvers lack self-awareness and insight that places them at-risk. 
The cross-case analysis facilitated the exploration of initial and sustained attention (Guerra, 2006, 2009) adding clarification to the dimensions of social cognitive, cultural context, and goal investment. This analysis began with the examination of the more cohesive picture of reciprocal interactions with the environment, person and behavior, products of the problem solving exchange. Bandura $(1982 ; 1986 ; 2001)$ explains this framework as triadic reciprocality, a social cognitive interactive exchange and a means of illustrating perceived self-efficacy, one's capabilities to organize, develop plans and create change in behavior and/or thought.

\section{Research Question: (1) Identified social cognitive challenges: What do bilingual teacher candidates identify as social cognitive concerns?}

\subsection{Social Cognitive Concerns - Initial Attention}

The reported social cognitive challenges are presented in Table 3. Alicia described a busy, active, and fast paced environment. She reported, "Getting work done, time management, managing finances, family troubles, and finishing school" as primary challenges. Cultural rituals, beliefs and social interactions were woven in her personal narrative such as her ranking of family troubles atop her of reported challenges (Clark, Jackson, \& Prieto, 2011). Students organize their daily academic experiences in a dynamic process that includes self in context, action and outcomes (Skinner \& Pitzer, 2012).

Katia defined four major concerns, “dealing with Mom's recovering, my brother's struggle to take over dad's company, ending of semester, and dealing with work". The sheer number of items addressing family concerns and the types of concerns suggests that her personal environment is of greater importance than work or school.

Maggie reported herself as being very socially active, having a large amount of friends paired with limited family support. Examining her environmental presentation, it is clear that she reported environmental variables aligned with her self-description. She identified, "assignments, responsibilities, fundraiser, events, finals, meetings, family and home" as environmental variables and challenges. Implied at the deeper level are her values of responsibility, cultural obligation and family. These exchanges are visible in the environmental narratives that each participant presented.

Alicia presented herself as willing to consider a change, new self-management options and someone who is secure enough to evaluate what will and will not work for her. She explored values and actions with options including "buy a planner, make lists, set reminders for work/chores and make a list of things already done (motivation)". Of interest was her lining out of "make a list of things already done (motivation)" option.

Katia expressed her value system as self-care oriented as she contemplated taking time off from work, creating a new schedule and/or maybe going to work half days rather than full days. As such, work is important but it is not the most important activity occurring in her life. Her responses suggest that she recognizes that taking care of herself and lowering her level of stress at work is important and critical to educational and professional success and therefore should be addressed.

Maggie appeared to be wrestling with herself as she explored how to begin addressing change as it related to school. She reported, "turn it in late, give up, do one assignment at a time," and then almost pausing in her personal individual place she appeared to come to a realization, she identified her deficit and real challenge, "not keeping track of dates".

Alicia processed her challenge behaviorally as she reality-tested what she could imagine herself doing. Her behavioral investments included, "buy planner/calendar to be able to jot down any important dates/due dates". She then recorded "Better organized" when prompted to reality test.

Katia processed what she could do as she considered, "I would talk to my boss and figure out a way to get some time off; working out a new schedule may result in less money but it is something that I am willing to do. Instead of going all day at time I could go half a day and therefore give me time to myself'.

Maggie addressed what will happen if she continues to turn things in late, she will receive low grades. She then considered what will happen if she gives up, she "will not be able to succeed; and get further behind". There was a pause in her reflecting and she concluded her behavioral ruminations with the thought that she could "use a calendar to do $2-3$ assignments a day".

\subsection{Cross-case Analysis}

Although each teacher candidate reported unique social and contextual challenges, common patterns emerged across cases. All three Latina Bilingual teacher candidates reported family and personal challenges within the "list and listen" phase of the LIBRE model. Family was identified as a major concern for all three Latina bilingual teacher candidates; even Maggie who reported a separation from family identified family as a challenge. Similarly, community was expressed as concern: Alicia identified this as family troubles; dealing with Mom's recovery, brother's attempts to take over the family business, and work. While this challenge is a family concern, it also reflects her cultural value and 
commitment to family responsibilities and caring for family over self. Maggie expressed it in fund-raising commitments, meetings, and family.

Table 3. Social Cognitive Cultural Initial Attention

\begin{tabular}{|c|c|c|c|}
\hline & Environment & Person & Behavior \\
\hline Alicia & $\begin{array}{ll}\text { - } & \text { Getting work done. } \\
\text { - } & \text { Time management. } \\
\text { - } & \text { Managing my finances. } \\
\text { - } & \text { Family troubles. } \\
\text { - } & \text { Finishing school. }\end{array}$ & $\begin{array}{ll}- & \text { Buy a planner. } \\
\text { - } & \text { Make lists. } \\
& \text { Set reminders for } \\
& \text { work/chores. } \\
\text { - } & \text { Make a list of things } \\
& \text { already done } \\
& \text { (motivation). } \\
\end{array}$ & $\begin{array}{l}\text { - } \quad \text { Buy a planner/calendar to be able to jot down } \\
\text { any important due dates. } \\
\text { *Better organized* }\end{array}$ \\
\hline Katia & $\begin{array}{l}\text { Dealing with my mom's } \\
\text { recovering. } \\
\text { My brother's struggle to take } \\
\text { over dad's company. } \\
\text { - } \quad \text { Ending of the semester. } \\
\text { Dealing with work. }\end{array}$ & $\begin{array}{l}\text { - Take some time off } \\
\text { from work. } \\
\text { Work out a new } \\
\text { schedule. } \\
\text { - Maybe go half a day } \\
\text { instead of a whole day. }\end{array}$ & $\begin{array}{l}\text { Talk to my boss and figure out a way to get } \\
\text { some time off. } \\
\text { - Working out a new schedule may result in } \\
\text { less money but it is something I am willing to } \\
\text { do. } \\
\text { - Instead of going all day at a time, I could go } \\
\text { half a day and give me time to myself. }\end{array}$ \\
\hline Maggie & $\begin{array}{ll}\text { - } & \text { Assignments. } \\
\text { - } & \text { Responsibilities. } \\
\text { - } & \text { Fundraising } \\
\text { - } & \text { Events. } \\
\text { - } & \text { Finals. } \\
\text { - } & \text { Meetings. } \\
\text { - } & \text { Family. } \\
\text { - } & \text { Home. } \\
\end{array}$ & $\begin{array}{l}\text { - } \quad \text { Turn it in late. } \\
\text { - } \quad \text { Give up. } \\
\text { Do one assignment at a } \\
\text { time. } \\
\text { Not keeping track of } \\
\text { dates. }\end{array}$ & $\begin{array}{l}\text { - Low grades. } \\
\text { - Will not be able to succeed. } \\
\text { - } \quad \text { Get further behind. } \\
\text { - Use a calendar to do 2-3 assignments a day. }\end{array}$ \\
\hline
\end{tabular}

All three Latina Bilingual teacher candidates reported diverse challenges and each listed multiple concerns rather than focusing on a selected or a few related areas of concern. This suggests that these Latina Bilingual teacher candidates all experience a multitude of concerns and challenges spanning across languages, cultures, and contexts. Still, the concern areas were fairly consistent across the three teacher candidates with each reporting familial, financial, and school related challenges. While the three teacher candidates' maintained distinct social-cultural-realities, they each showed an initial investment evidenced by their detailed responses (D'Zurilla \& Goldfried, 1971).

\section{Research Question: (2) Identified goals - what are their goals?}

Table 4. Goal Investment-Sustained Attention (Guerra, 2009)

\begin{tabular}{|c|c|c|c|}
\hline & Goal & Plan & Accountability \\
\hline Alicia & $\begin{array}{l}\text { What can I do the } \\
\text { help manage my time } \\
\text { better? }\end{array}$ & $\begin{array}{l}\text { - I can buy a planner. } \\
\text { - I can carry the planner with me to } \\
\text { make notes on important dates. } \\
\text { - With post-it notes, I can re-write the } \\
\text { dates and post them around the } \\
\text { house as reminders. }\end{array}$ & $\begin{array}{l}\text { Friday before work on } 4 / 20 \text { or Monday on } \\
\text { 4/23, after work (at 10:00), go to HEB or } \\
\text { Wal-Mart to buy a planner and post-it notes. }\end{array}$ \\
\hline Katia & $\begin{array}{l}\text { How can I deal with } \\
\text { the stress of my job? }\end{array}$ & $\begin{array}{l}\text { - Have a meeting with my boss and } \\
\text { coworkers to see who needs or wants } \\
\text { more hours. } \\
\text { - I would explain that I feel too } \\
\text { stressed since everything falls on my } \\
\text { shoulders at work. } \\
\text { I would ask for some days off and } \\
\text { see about reducing my weekly work } \\
\text { schedule. }\end{array}$ & $\begin{array}{l}\text { - } \quad \text { By the end of the week, I will set a meeting } \\
\text { with my boss and explain everything to let } \\
\text { them know what I need as of now. }\end{array}$ \\
\hline Maggie & $\begin{array}{l}\text { How do I begin to } \\
\text { prioritize? }\end{array}$ & $\begin{array}{l}\text { - Use calendar to do } 3 \text { assignments per } \\
\text { day. } \\
\text { - } \quad \text { Call a classmate. } \\
\text { - Communicate with my family and } \\
\text { let them know my limitations. }\end{array}$ & $\begin{array}{l}\text { - } \quad \text { Set timeframe and put it in the calendar and } \\
\text { stick it on my bathroom mirror. } \\
\text { - } \quad \text { Call a friend on a daily basis to get update. } \\
\text { - } \quad \text { Talk to family on the weekend about my plan. }\end{array}$ \\
\hline
\end{tabular}




\section{$9.1 \mathrm{Goal}$}

Alicia reported her goal as: "What can I do to help me manage my time better?" In analyzing this goal, what is considered is her focus, which is clearly stated and within her control. Also important is in terms of efficacy, she has sufficient detail to complete this goal should she so select. Katia's goal was revealed with the question: "How can I deal with the stress of my job?" It is self-reflective, within her control and addresses her confidence in herself as an employee and as a person. Maggie's goal is in line with busyness: "How do I begin to prioritize?" She appears self-aware and she too has identified a goal that is within her control to address. The reported goal was not the only thing analyzed as the level of detail and self-imposed accountability was also examined. A non-invested or poor problem solver will not create a plan and /or timeline (Gagne, 1959). These women on the other hand, listed challenges and listed realistic goals and plans. Bilingual teacher candidates' self-reported goals are listed in Table 4.

\subsection{Plan}

Alicia's goal included a self-commitment as ability: "I can buy a planner / calendar. I can carry the planner w/ me to make notes on important dates. Then w/ the post its, re-write them and post around room, kitchen, bathroom". The plan is detailed and specific to provide the checklist to go forward in resolving her identified concern.

Katia's plan involved the following statements in which she presented herself as practicing and as if the interactions have already been completed: "I would have a meeting with by boss and also talk to my coworkers to see who needs or wants more hours. I would explain that I am too stressed since everything falls on my shoulders at work and I would ask for some days off and see about reducing the amount of hours per week".

Maggie's plan was to "use a calendar to do 3 assignments per day and to call a classmate and communicate with family to let them know my limitations". The plan is straightforward and it is congruent with her value place on friends and friendship and support. All three bilingual teacher candidates under examination planned to incorporate the use of planner, calendar, or to do list to accomplish tasks and challenges. Notably, candidates placed responsibility with themselves to accomplish the tasks and challenges at hand.

\subsection{Accountability Measure}

Alicia's timeline addressed her commitment to herself and to the identified challenge. As such, it read: "Friday before work $4 / 20$ or Monday 4/23 after work (at 10:00) go to HEB or Wal-Mart to buy planner \& post its. While it is not the strongest timeline because she presented an either-or option, it does provide an accountability measure that by the end of the week, she will be able to self-reflect and monitor her commitment to her resolution plan. Katia's detailed measure is: "By the end of next week I will set a meeting and explain everything to let them know what I need as of now. Her tone is direct and there is a level of imbedded responsibility. Maggie's accountability follows her identified plan, which includes: "set timeframe and put it on the calendar and stick on my bathroom mirror; call a friend on daily basis to get update and talk to family on the weekend about plan".

10. Research Question: (3) Investment and Engagement - what is the initial and sustained attention for each teacher candidate as expressed in their problem identification, solution generation, and goal setting (engagement styles)?

\subsection{Engagement}

Alicia, Katia and Maggie each appeared invested and engaged as measured by the detail and specificity of responses beginning in the List and Listen phase to the final Encourage phase of the LIBRE activity and thus exhibited an actual engagement style in their problem solving. Discrete areas of concern were identified and were within each of the three participants' control. These identified concerns became the focal point in the establishment of goals and detailed resolution plans for each participant. While specific content varied, as did their social context and culturally identified environments, self-awareness, investment, and monitoring was seen across cases.

All three participants exhibited initial and sustained attention to develop a plan with a timeline to benchmark their responsibility in resolving their identified challenges, thus a consistency of actual engagement style. Actual engagement styles are visible in the identified problem expressions (within his/her control), the problem approach assumed (approach oriented) and in the expressed relation between the two. In other words, their social cognitive cultural exchanges and demonstrated approach strategy reflect the pattern of an actual engagement style.

\section{Research Question 4: What can be learned from these case studies about the role of family, culture, and psychology in the decision to pursue teaching?}

Three teacher candidates' identified problems, goals, and task engagement was examined through descriptive case study analysis. The cross case analysis showed family concerns to be a major challenge for all three cases. Consistency across cases shows the importance of family for this cultural group. Moreover, each teacher candidate reported an underlying 
responsibility to family.

Consistent with research with Latino populations, the role of family was a major consideration for each of the teacher candidates. Similarly, culture was noted as a factor in the decision made to pursue teaching as noted during their interviews. We also saw persistence across all three cases as measured by responses and detailed problem resolutions. This persistence is cross-validated with their progression in their program of study. In addition, we saw that these teacher candidates took matters into their own hands and despite voicing multiple concerns across settings and involving multiples persons within their social system, they resolved to broach and solve their challenges on their own. Each woman relied on internal (self) resources to overcome obstacles.

\section{Research Question 5: What can be learned from their problem solving approaches?}

Description of social contextualized problems and task engagement offers insight to sociocultural cognitive considerations. For example, Alicia reported concerns about "getting work done, time management, managing finances, family trouble, and finishing school and "being able" to pay "for it". She is aware of her sociocultural and cognitive responsibilities. The case study presentations offer information about each individual's values and goals toward school success along with their strategy used to approach processing challenge. There is maintenance of balance (Heider, 1958) in facing problem needs, as engagement styles and coping strategies support resilience. The design of the LIBRE Model activity encourages active participation, engagement, and internal dialogue (Guerra, 2009).

\section{Discussion and Implications}

\subsection{Discussion}

The student demographic is growing in cultural and linguistic diversity while the teacher workforce is composed of predominately white females (Schmitz et al., 2012). This mismatch is seen as problematic for the learner and for the teacher as navigating cultural and linguistic diversity is complex. The sheer volume and complexities in the reported problems herein suggest that effective problem solving is necessary for educational, professional, and personal success. As problem solving is recognized as one of the important cognitive processes, the current study sought to examine the types of problems and resolution plans bilingual teacher candidates reported as a first step toward identifying effective problem solving characteristics. In this cross-case analysis we saw that each bilingual teacher candidate possessed good problem solving skills as seen in their task engagement and well-developed solutions and goals. Additionally, each teacher candidate noted the usefulness of the LIBRE problem-solving tool as a way to prioritize and visualize plans.

Another consistency was found in their description of their experiences as a fight and uphill battle. Their rich descriptions coincide with research that has shown leaks in every phase of the educational pipeline often described as swimming against a current (Flores et al. 2007). This fight however, allows these teacher candidates to better relate with their students who are often in the throes of their own fights and struggles. In this respect, adversity can be seen in a positive light and as an asset from which shared experience can build on effective problem solving and also lead to modeling of effective problem solving through the sharing of the essential characteristics and skills critical to survival.

Each of their "fights" appeared to involve finding balance and a way to successfully do it all. It appears that for these Latina Bilingual teacher Candidates, needing to manage it all was a source of stress and anxiety. Something that all too many a Latina experience (Saldana et al., 2013). Moreover, these women were also doing it all virtually independently. Those who were experiencing familial strife, found acceptance and support outside the family but still showed the importance of positive interpersonal relationships in accomplishing and successfully resolving challenges (Sanchez-Burks, Nisbett, \& Ybarra, 2000). These women showed the primacy of family in that all three noted this as a concern. They also demonstrated the value in listing challenges and generating solutions as a means for effective problem solving. These women however, were more likely to have to resolve conflict on their own, that is, relying on their own internal resources. These women through personal experiences and successes showed teaching and selfefficacy and the belief to be able to accomplish it all. This belief in oneself appeared to move them to action and to conflict resolution.

Their stories tell of the need to rely on personal strengths as the push and pull and struggle to find balance is particularly salient for Latina Bilingual teacher candidates. Although multiple problems were noted, more solutions were generated and again, those solutions involved internal resources and personal agency. Previous research with the LIBRE Model has shown four distinct engagement approaches ranging from a venting approach where problems are listed with no clear plans to the actual approach shown herein where an equal number of challenges and solutions are generated (Castro-Villarreal \& Guerra, 2012). This approach and response pattern is theorized to demonstrate commitment and resolve to problem resolution.

To support this theory, post LIBRE Model interviewing suggests that the tool does help in problem identification and solution generation. In fact, all three teacher candidates described the tool as a "life saver" and a visual method for 
identifying problems and generating solutions. Maggie reported the reality-testing component to aid in the identification of realistic and attainable goals and solutions.

\section{2 Limitations}

While case studies are designed to elicit phenomenological and experiential information, data are limited by the case study methodology with regards to generalizability and validity. However, in the current study data triangulation was utilized to support and augment information obtained in the LIBRE responses. Moreover, to attempt to uncover personal, social cultural, and interpersonal experiences that enable professional and educational success, in depth case study is necessary and appropriate methodology for the research questions under investigation.

\subsection{Conclusions}

Problem solving skills play an influential role in successfully navigating one's environment and appear to involve personal experiences, behavior, and environmental influences (Kim \& Sin, 2007). The examined narratives showed that flexibility and organization are critical to effective problem solving (Swanson et al., 1990). Problem solving utilizing the LIBRE problem solving tool supports recent findings in problem-based learning and recommendations for problem-solving to involve authentic real life situations to enable learners to gain knowledge from personal and meaningful life experiences (Jolly \& Jacob, 2012).

The completed LIBRE problem solving tools, offered key insights into the types of problems bilingual teacher candidates experience and how they go about prioritizing and setting goals. Initial and sustained engagement was visible beginning with the problem identification process and ending in the plans and goals. Successful problem resolution demonstrates the importance of identifying and prioritizing problems. The shared narratives provide additional support for the primacy of family in Latino culture and that interdependency should be viewed as an asset rather than a problem. The shared narratives also highlight the continued struggles of this population while their resolve and determination illuminates a resiliency and drive like no other. Although problem solving can sometimes be problem focused, this research along with the use of the LIBRE problem solving tool shows how problems can be reframed and re-conceptualized as assets and offer invaluable practice for successful management of the complex problems teachers will inevitably face in the classroom. Taken together, this line of research provides a training focus towards teacher challenges and experiences to foster engagement and reality testing for improved flexibility and organization in attending to and solving complex problems.

\section{References}

Anderson, J. R. (1993). Problem solving and learning. American Psychologist, 48(1), 35-44. http://dx.doi.org/10.1037/0003-066X.48.1.35

Au, K. H., \& Blake, K. M. (2003). Cultural identity and learning to teach in a diverse community: Findings from a collective case study. Journal of Teacher Education, 54(3), 192-205. http://jte.sagepub.com/content/54/3/192

Bandura, A. (1982). Self-efficacy mechanism in human agency. American Psychologist, 37(2), 122-147. http://dx.doi.org/10.1037/0003-066X.37.2.122

Bandura, A. (1986). Social foundations of thought and action: A social cognitive theory. Englewood Cliffs, NJ: Prentice Hall.

Bandura, A. (2001). Social cognitive theory: An agentic perspective. Annual Review of Psychology, 52, 1-26. http://www.annualreviews.org/doi/pdf/10.1146/annurev.psych.52.1.1

Basile, C., Olson, F., \& Nathenson-Mejia, S. (2003). Problem-based learning: Reflective coaching for teacher educators. Reflective Practices, 4, 291-302. http://dx.doi.org/10.5539/ies.v5n3p205

Briones, D. F., Heller, P. L., Chalfant, H. P., Roberts, A. E., Aguirre-Hauchbaum, S. F., \& Farr, W. F., (1990). Socioeconomic status, ethnicity, psychological distress and readiness to utilize a mental health facility. American Journal of Psychiatry, 147, 1333-1340.

https://login.libweb.lib.utsa.edu/login?url=http://search.proquest.com/docview/220466893?accountid=7122

Castro-Villarreal, F., \& Guerra, N.S. (2012). Preservice teachers' problem solving: A study of problem identification and engagement style using the LIBRE model. Teacher Education and Practice, 25(3), 350-369.

Clark, E. R., Flores, B. B. (2005). Creating a just society: Multicultural teacher education and the changing classroom. Teacher Education and Practice, 18(3), 315-332. https://ucat.lib.utsa.edu/vwebv/holdingsInfo?bibId=380247

Clark, E. R., Jackson, L. G. \& Prieto, L. (2011). Identity: A central facet of culturally efficacious bilingual education teachers. In B. B. Flores, R. S. Hernandez, \& C. E. Riojas, (Eds). Teacher preparation for bilingual student population. (pp. 27-39.) New York: Routledge. 
Connell, J. P., \& Wellborn, J. G. (1991). Competence, autonomy and relatedness: A motivational analysis of self-system processes. In M. Gunnar \& L. A. Sroufe (Eds.), Minnesota symposium on child psychology, Vol. 23 (pp. 43-77). Chicago: University of Chicago Press.

Cushman, K. (2006). First in the family: Your college years, advice about college from first-generation students. Providence, RI: Next Generation Press.

Darling-Hammond, L. (2004). The color line in American education: Race, resources, and student achievement. W. E. B. DuBois Review: Social Science Research on Race, 1(2), 213-246. https://login.libweb.lib.utsa.edu/login?url=http://search.proquest.com/docview/214850898?accountid=7122

Day, C., \& Leitch, R. (2001). Teachers' and teacher educators' lives: The role of emotion. Teaching and Teacher Education, 17(4), 403-415. http://dx.doi.org/10.1016/S0742-051X(01)00003-8

D'Zurilla, T. J., \& Goldfried, M. R., (1971). Problem solving and behavior modification. Journal of Abnormal Psychology, 78(1), 107-126. http://dx.doi.org/10.1037/h0031360

Evans, E. D., \& Tribble, M. (1986). Perceived teaching problems, self-efficacy, and commitment to teaching among preservice teachers. Journal of Educational Research, 80(2), 81-85. http://www.jstor.org/stable/40539614

Falicov, C. J. (1996). Mexican families. In M. McGoldrick, J. Giordano, \& J. Pearce (Eds.), Ethnicity and family therapy (pp. 169-182). New York: Guilford Press.

Flores, B., Clark, E., Claeys, L., \& Villareal, A. (2007). Academy for teacher excellence: Recruiting, preparing, and retaining Latino teachers through learning communities. Teacher Education Quarterly, 34(4), 258-280.

Gagne, R. M. (1959). Problem solving and thinking. Annual Review of Psychology, 10(1), 147-172. http://www.annualreviews.org/doi/abs/10.1146/annurev.ps.10.020159.001051

Glaser, B. G., \& Strauss, A. L. (1967). The discovery of grounded theory: Strategies for qualitative research. Chicago: Aldine.

Glaser, B. G., \& Strauss, A. L. (1970). Discovery of substance theory. In W. Filstead (Ed.), Qualitative Methodology. (pp. 288-297). Chicago: Rand McNally.

Guerra, N. (2006). The LIBRE problem-solving model: A practical approach to problem-solving and decision-making for teachers and teacher educators. Texas Teacher Educator's Forum, 29, 9-14.

Guerra, N. (2009). Illustrations of engagement styles: Four teacher candidates. Teacher Education \& Practice, 22 (1), 95-117.

Guerra, N., \& Bollinger (2011). Engagement styles in consultation: LIBRE model problem-solving tool. The Dialog, Spring 40(1), 4-8.

Haycock, K. (2002). Toward a fair distribution of teacher talent. Equity and Opportunity, 60(4), 11-15. https://login.libweb.lib.utsa.edu/login?url=http://search.ebscohost.com/login.aspx?direct=true\&db=tfh\&AN=8627 $393 \&$ scope $=$ site

Heider, F. (1958). The psychology of interpersonal relations. New York: Wiley.

Hogan, T., \& Rabinowitz, M. (2009). Teacher expertise and the development of a problem representation. Educational Psychology, 29(2), 153-169. http://www.retc.fordham.edu/images/academics/education/gse_cnt_div/blumberg/teacher_expertise_article_1.pdf

Hollins, E.R. \& Guzman, M.T. (2005). Research on preparing teachers for diverse populations. In M. Cochran-Smith \& K.M. Zeichner (Eds.), Studying teacher education: The report of the AERA panel on research and teacher education (pp. 477-548). Mahwah, NJ: Erlbaum/AERA.

Hsieh, P. H., Sullivan, J. R., \& Guerra, N. (2007). Closer look at college students: Self-efficacy and goal orientation. Journal of Advanced Academics, 18, 454-476.

Irizarry, J. (2011). En la lucha: The struggles and triumphs of Latino/a preservice teachers. Teachers College Record, 113(12), 28-34. https://www.tcrecord.org/Content.asp?ContentID=16206

Jolly, J., \& Jacob, C. (2012). A study of problem based learning approach for undergraduate students. Asian Social Science, 8(15), 157-164. http://ccsenet.org/journal/index.php/ass/article/view/22657

Kilbane, C. R. (2008). Preservice teachers' application of a problem-solving approach on multimedia cases. Action in Teacher Education, 29(4), 15-26.

https://login.libweb.lib.utsa.edu/login?url=http://search.ebscohost.com/login.aspx?direct=true\&db=eft\&AN=50802 
$5203 \&$ scope $=$ site

Kim, K., \& Sin, S., (2007). Perception and selection of information sources by undergraduate students.Journal of Academic Librarianship, 33(6), 655-665. http://dx.doi.org/10.1016/j.acalib.2007.09.012

Llagas, C., \& Snyder, T.D. (2003). Status and trends in the education of Hispanics. Washington, DC: U.S. Department of Education, National Center for Educational Statistics. (NCES 2003-008).

Lopez, M. H. \& Fry, R. (2013). Among recent high school grads, Hispanic college enrollment rate surpasses that of whites. Washington, DC: Pew Hispanic Center.

Mayer, R. E., \& Wittrock, M. C. (2006). Problem solving. In P. A. Alexander \& P. H. Winne (Eds.), Handbook of Educational Psychology (2 ${ }^{\text {nd }}$ ed., pp. 287-303). Mahwah, NJ: Erlbaum.

Meichenbaum, D. (1977). Cognitive behavior modification: An integrative approach. New York: Plenum.

Merriam, S. B. (2009). Qualitative Research: A Guide to Design and Implementation. San Francisco, CA: John Wiley \& Sons.

Saldana, L., Castro-Villareal, F., \& Sosa, E. (2013). “Testimonios” of Latina junior faculty: Bridging academia, family, and community lives in the academy. Educational Foundations, 27(1), 31-48.

https://login.libweb.lib.utsa.edu/login?url=http://search.ebscohost.com/login.aspx?direct=true \&db=eft\&AN=93262 $482 \&$ scope $=$ site

Sanchez-Burks, J., Nisbett, R., \& Ybarra, O. (2000). Cultural styles, relational schemas and prejudice against outgroups. Journal of Personality and Social Psychology, 79(2), 174-189. http://search.proquest.com/docview/60393683?accountid=7122

Schmitz, S. A., Nourse, S. W., \& Ross, M. E. (2013). Increasing Teacher Diversity: Growing your own through partnerships. The Education Digest, 78(5), 59-63.

http://search.proquest.com/docview/1349974868?accountid=7122

Skinner, E. A., \& Pitzer, J. R. (2012). Developmental dynamics of student engagement, coping, and everyday resilience. In S. L. Christenson, A. L. Reschly, \& C. Wylie (Eds.), Handbook of Research on Student Engagement (pp. 21-44). New York: Springer.

Swanson, H. L., O’Connor, J. E, \& Cooney, J. B. (1990). An information processing analysis of expert and novice teachers' problem solving. American Educational Research Journal. 27(3), 533-556. http://www.jstor.org/stable/1162935

U.S. Department of Education, National Center for Education Statistics. (2012). Digest of Education Statistics, 2011 (NCES 2012-001), Introduction and Chapter 2; U.S. Department of Education, National Center for Education Statistics, Schools and Staffing Survey, Teacher Data Files, 2007-08.

U.S. Department of Education, National Center for Education Statistics. (2013). The Condition of Education 2013 (NCES 2013-037), English Language Learners.

Zimmerman, B. J. (2000). Attaining self-regulation: A social cognitive perspective. In M. Boekaerts, P.R. Pintrich, \& M. Zeidner (Eds.), Handbook of self-regulation (pp.13-39). San Diego: Academic Press.

Zimmerman, B. J. \& Schunk, D. H. (2004). Self-regulation intellectual processes and outcomes: A social cognitive perspective. In D. Y. Dai \& R. J. Sternberg (Eds.), Motivation, emotion, and cognition: Integrative perspectives on intellectual function and development. (pp. 323-350). Mahwah, NJ: Erbaum.

\section{(cc) B B}

This work is licensed under a Creative Commons Attribution 3.0 License. 